\title{
Reflections and looking ahead for CSCL: digital infrastructures, digital tools, and collaborative learning
}

\author{
Sten Ludvigsen ${ }^{1} \cdot$ Rolf Steier ${ }^{1}$ \\ Published online: 29 November 2019 \\ (C) International Society of the Learning Sciences, Inc. 2019
}

After four years as Editor-in-Chief and Managing Editor, respectively, we have read, dwelled on, and made judgements about several hundred CSCL papers. (As Managing Editor, Rolf has worked with the accepted manuscripts in addition to review work.) We believe that this overview has given us a deeper insight into CSCL as a developing field of knowledge and into what CSCL researchers want to achieve and emphasize. As an interdisciplinary field, CSCL changes over time as new technologies emerge and the field itself shifts, modifying its conceptual, methodological, research, and design perspectives as well as its empirical concerns.

CSCL is one of the two strands of research in the learning sciences; the other strand manifesting itself through The Journal of the Learning Sciences and the associated conferences. Though there is a substantial overlap between these two research strands, with human learning as a core issue for both, CSCL is defined as a triad structure of collaboration that is mediated by a computational artifact (participant - artifact - participant). In this editorial, we will emphasize some significant ideas that we have observed in the IJCSCL and how they might influence the future of the field. We will not attempt to provide an extensive description of the papers published in the period from 2016 to 2019. However, both the original papers and the squibs published during this period are the backdrop for this editorial.

\section{Historical development of CSCL and foundational issues}

In the late 1980s and early 1990s, CSCL was conceptualized as a possible and nascent field of knowledge. Almost 30 years later, CSCL is a well-established field that cuts across social, educational, learning, and computer sciences. However, collaboration between humans and artefacts is not a new phenomenon. In most CSCL studies, collaboration is part of the digital and educational design, which means that collaboration should serve a specific purpose in both learning processes and outcomes. The digital aspects, however, are historically new. CSCL, as we see it, is a field of study that aims to understand the most important aspects of human

Sten Ludvigsen

s.r.ludvigsen@iped.uio.no

1 Department of Educational Sciences, University of Oslo, Oslo, Norway 
development and cognition. Human development comprises social interaction and artifacts involved in meaning making. The formation of intersubjectivity (Rommetveit 1998; Tomasello 1999) creates the foundation for humans to be able to communicate and learn - in other words, to create the conditions for the development of rationality in society, in institutions, and between humans in all settings.

Intersubjectivity is a non-trivial issue in CSCL. Many different concepts are used to describe intersubjective processes and mechanisms, like joint attention, common ground, and shared knowledge. In recent years, it has become clear that joint attention is needed to solve complex tasks; however, rather than being a common property that participants bring with them into such tasks, joint attention emerges as participants are involved in solving problems together. Intersubjectivity is not only established through human communication but equally to the coupling between representational artifacts, practices, and the social systems in which humans participate. Stepping back, the development of human civilization is dependent on such representational artifacts in the accumulation of knowledge and our internal and external memory systems. However, digital infrastructures and tools are gradually taking over the function of external systems of memory and human remembering processes (Donald 1991; Bowker and Star 1999).

\section{Students learning in complex CSCL settings}

Two of the most important competences that students need to appropriate in today's society and educational institutions are the capacities to frame problems and to investigate them. These challenges are part of what are often called hard-to-learn problems (or 'wicked problems'). Representations of knowledge are often distributed in multiple resources rather than in a single textbook. Resources need to be explored and integrated into a task structure by students and teachers. Students use multiple resources with regard to content, collaboration, and digital tools and environments, which presuppose an advanced student agency. Agency consists of cognitive, social, and emotional aspects, and students need to develop their capacity to learn advanced concepts and to explore complex problems for which the solutions are not given. In other words, students need to develop a critical agency. Therefore, the basic question for CSCL is how can teachers, institutions, and the designers of digital infrastructures, tools, and tasks support such a development?

Such foundational questions have been addressed in CSCL through numerous studies over the past thirty years in controlled experiments, design-based research, and natural contexts. Studies based on knowledge-building, cognitive, socio-cognitive and socio-cultural stances have advanced our thinking on how we can better prepare students for the future. They show us that designing for advanced human learning is not a trivial effort. Even in controlled experiments, social and cultural aspects influence how students respond to new challenges, which may be due to socialization, prior knowledge, and experiences. A majority of such studies have focused on the classroom (both in person and online) as a primary learning context, but other settings are conceptualized as places for learning. We observe growing attention given to museums (e.g. Roberts and Lyons 2017), social media (e.g. Holtz et al. 2018), as well as homes and neighborhoods (e.g. Silvis et al. 2018) as important everyday contexts. Given that students and other actors live in diverse contexts and also that institutions differ locally, nationally, and globally, the CSCL community should continue to ask questions about how people learn as contexts and settings change over time. This means not only that the 
CSCL settings we attend to as researchers are shifting, but also that learners themselves are increasingly unconfined to static learning situations.

\section{New digital landscapes_formation of platforms}

Let us place the digital in the foreground of our perspective and dwell on the concept of digital infrastructures and tools for CSCL. Only a few CSCL papers have placed digital infrastructures in the foreground. We believe that in the future, the field needs to develop a better understanding of how digital infrastructures influence the selection of digital tools and their use. In computer science, many contributions label digital infrastructures as heavyweight information technology (IT), while software that directly supports actions and activities is referred to as lightweight IT (Bygstad and Hanseth 2018). Hence, heavyweight IT creates new conditions for the design and use of lightweight digital tools. Especially for real-world studies that aim to use large amounts of data for analytics directed toward teachers and students (or, more generally, actors involved in CSCL settings), digital infrastructures are very important. The interdependencies in the interactions between the two digital layers and the collaboration between the involved actors need more attention in CSCL studies. Given that the interplay between digital infrastructures and tools is likely to increase, we need units of analysis that include all three layers: infrastructure, tool, and human. Digital platforms for learning, which connect the digital infrastructures with digital tools, thus also require more attention. The CSCL field needs to explore questions about the types of learning inscribed in the new types of platforms as well as the implications for students' collaborative activities.

Just as a digital perspective creates a need for the refinement and possible expansion of units of analysis, so too does taking an institutional perspective. An institutional perspective takes socio-cultural, interactional, and individual layers into account, including the digital tools involved in the performed actions (Ludvigsen and Arnseth 2017; White 2018). The CSCL agenda addresses what, why, and how learning occurs. These questions are based on the stance that learning is supported and that participants' learning always occurs in specific situations which include other participants and/or (computational) artifacts.

In CSCL, concepts like scripts, scripting, prompts, orchestration and representations are used to describe how specific types of support can mediate participants' learning processes and outcomes. The support can be directed by content, self-regulation, and social regulation and can be realized as specific designs intended to support social, emotional, and cognitive advancements. In many CSCL studies, the support is intended to direct content regulation and meta-regulation. However, support is not only a feature of digital design, but also accomplished through social and educational designs, such as group composition, students' roles, and scripts for argumentation and forms of reasoning. Such support is often built into the overall educational design and prescribes the roles of the teaching and teachers. The number of studies that directly address teachers' roles and teachers as resources in the design of environments and practices is increasing rapidly. In fact, the recent special issue (ed. Matuk et al. In Press) explores teacher roles and practices in relation to orchestration technologies. In these cases, orchestration tools like dashboards are considered to facilitate and enhance teacher activities like monitoring and intervening in student activity. The institutional perspective gives us insight into how social norms and values affect learning, how knowledge is organized, how learning situations are organized and play out in interactions, and what kinds of experiences and knowledge participants bring with them to interactional encounters. 
From an institutional perspective, the main research focus is often social practices, with digital infrastructures and tools considered as conditions for human learning that become partly invisible in the analysis. This is why we also need more technology-centric studies that give new insight into how digital infrastructures (heavyweight IT) and digital tools (lightweight IT) create dynamic conditions for what participants actually do. Together, different epistemic stances, as discussed further in the next section, can give us a more robust understanding of the triadic structure that CSCL takes as its analytic premises.

\section{CSCL and learning sciences-where to locate human learning and cognition}

In their book chapter in which the development of the learning sciences is presented, Fischer et al. (2018) make an interesting claim. They argue, "When we speak of the learning sciences as aiming for holistic understanding of human learning, we take both epistemic and systems views" (Fischer et al. 2018, p.1). The epistemic view implies that learning sciences are rooted in multiple perspectives. While the other aspect, the systems view, is conceptualized as human learning located in a "bio-socio-cultural hybrid system" (Fischer et al. 2018, p. 1). Puzzled by these claims, we asked ourselves what they mean for CSCL. Often, in the social sciences, one distinguishes between macro-, meso- and micro-phenomena. Usually human learning is treated as micro-phenomena, comprising the specific actions and activities performed by participants. The actions establish the interdependencies that are constitutive for learning. While biology certainly creates foundations for human learning through dispositions, biological aspects do not determine what and how humans learn. For learning, social and cultural practices are much more important. By taking a holistic view that includes elements of social systems and digital infrastructures, we can advance our understanding of human learning - built on a foundation of social practices. This means that social practices should be understood as action-technology interdependencies that create hybrid systems over time and create structural conditions for learning.

\section{CSCL at scale and impact}

Gerry Stahl commented in his 2015 editorial (2015) that it is difficult to design and introduce CSCL environments at scale in institutions like schools. Can the CSCL field scale toward societal impact? Or, in other words, how can we impact human learning in broader educational settings?

Some CSCL researchers claim that CSCL is not able to influence schooling in many countries. For example, this argument was put forward by Wise and Schwarz (2017) among their eight provocations for the field. However, Hod et al. (2018) strongly argue for the possibility of influencing teaching and learning in schools (and school systems), stating that extending design-based research to what they define as a design-centric research practice partnership can influence school practices. In this approach, teachers, school leaders, designers of learning resources and researchers work together in multiple sites and school networks. Yet even if CSCL can contribute to the progress of such networks, it does not cover all aspects of schooling. Over the last six years, one of us, Sten, has been involved in the development of national policy in Norway (NOU 2015:8 2015) in which the learning sciences and CSCL are 
used as foundational but not complete approaches to improving teaching and learning. Within the field of CSCL, we do not have deep insight into issues such policy formation, curriculum development, school as a social and political institution, school leadership, etc. Hence, it is crucial that we make significant contributions in conjunction with other fields of knowledge. Indeed, the assumption that CSCL should influence schools directly seems rather naïve; single fields of study should not influence schools directly. Rather, we must build up of solid foundation of knowledge that schools can draw upon. That is, we can influence policy and school practices by developing knowledge for the renewal of schooling, teaching and learning by advancing our own theoretical and methodological approaches. In our work, we should develop models for how deep learning in and across subjects can be achieved. There may of course be translation work in making such models accessible and actionable for policymakers, but we should have more a positive view of our own contributions - they can improve studentlearning across the world.

\section{Dialogue and critical epistemic agency}

Many CSCL studies address the quality or productivity of talk and action in CSCL settings. One emerging trend in CSCL, barely seen thirty years ago, is the use of the notion of epistemic agency. Learning in educational settings has become more complex than before as students need to understand not only knowledge and concepts themselves, but also how they have been produced and can be used. Being able to verify claims has become essential for learners. Such verification can be seen as part of dialogues in which students/participants engage themselves and others in broader epistemic activities. In such activities, orientations toward new knowledge create common objects for group actions. The quality of dialogues in classroom settings is dependent both on spatial and temporal contexts for student talk and on the support of computational artifacts. In such spaces, students' epistemic orientations can be supported by the teacher and designed tools, environments, and infrastructures. Educational dialogues need to be connected to epistemic orientations for students to appropriate an understanding of complex tasks in and across knowledge domains.

\section{Design for variation}

In his 2015 editorial, Stahl (2015) argued that technological design in CSCL is directed toward the individual student rather than group practices. For us, this was a very interesting observation and an important argument for designing specific digital educational tools. Moreover, we emphasize that, in CSCL, we almost never design for variation in the student populations that we study. The papers by Slakmon and Schwarz (2014) and by Yang et al. (2016) are two papers that analyze low achievers directly. With the possibilities that digital platforms offer, the CSCL community could explore how to apply principles for adaptivity to individual students and groups of students. CSCL could take low achievers as important test cases for our capacity to design learning activities for all students. One could design for individual sequences of actions and specific sequences for group practices that are built on individual work. This personalized approach means both working by oneself and working together in dialogue with others with a high degree of epistemic orientation. 
In addition to variation among learners, another form of variation includes the frame of tools and resources. Such a direction does not imply that we need deeper investigations of specific technologies and infrastructures, but rather that we must recognize learning contexts as flexible, changing, and drawing on a variety of such resources that move in and out of relevance depending on the situation. The majority of studies in IJCSCL attend to a single tool or interface that mediates learning activities. Intervention studies typically rely on the introduction of a particular tool. Tchounikine (2019) argues that learner agency should not only be considered to inform processes within a given activity, but should be extended to allow learners to select their own tools and resources. A CSCL design would thus include the interaction between varying resource-choices of learners. Similarly, Steier et al. (2019) propose attending to the improvised representations of students which emerge outside of the intended CSCL design or framework. Collectively, this suggests that an emerging perspective in the field includes the expansion of what we consider to be designed activity.

\section{Future studies in CSCL}

We will still need robust empirical studies with strong theoretical foundations in cognitive, sociocognitive, and socio-cultural stances. A knowledge-building stance that varies in its theoretical perspective is also a line of CSCL that can advance the field. Such studies should take place in multiple contexts around the world. Without detailed process-oriented studies and studies that focus on specific features of support-enhanced learning, we will not make further progress.

We must also emphasize collaboration at scale. New platforms, digital infrastructures and tools make it possible to understand how designed environments and commercial software can be used to support a wide range of participants in their learning efforts. In this arena, we may see a breakthrough based on learning analytics, which, so far, we have seen few examples of in CSCL. The digital and institutional perspectives emphasized in this editorial may give ideas as to how such studies can be performed.

Finally, we require more studies that cross boundaries between various CSCL approaches. In particular, we need to understand the implications of digital platforms with heavyweight and lightweight IT for human learning and how we can design new types of learning environments.

Now we will present the papers in this issue.

\section{Socially shared regulation for learning - methodological challenges}

In the paper by Sanna Jävelä, Hanna Järvenoja, and Johanna Malmberg, they focus on capturing the dynamics of the cyclical nature of regulation. They address methodological concerns to improve the understanding of socially shared regulation, co-regulation, and self-regulation in learning. Many studies in the last 20 years confirm that self-regulation skills are needed for in-depth learning. Self-regulation can involve cognitive, social, and emotional aspects (Hadwin et al. 2018; Järvelä et al. 2016).

The complexities of regulation increase when considering the relationship between coregulation and socially shared regulation, as the authors acknowledge in this paper. The first issue is that regulation is not linear, which implies that it depends on cyclical adaptationsitself a non-trivial object of study. The second issue is how the three forms of regulationsocially shared, co-regulation, and self-regulation - together create productive learning. And the third is to capture socially shared regulation for learning in authentic settings. 
What could be the solution, or at least the way to understand and explain different forms of regulatory processes? The authors emphasize three aspects of the data that we need to take account of: (1) tracing actions over time, (2) the multidimensional aspects of action (social, cognitive, and emotional), and (3) the cyclical nature of regulation. Regulation normally varies in time and depending on tasks and how participants choose to take part in them. In CSCL, we need environments and tools to capture such data in order to make progress. Given that students do more and more work in digital infrastructures and environments, the CSCL community should aim for specific CSCL designs that can be tailored to enable the data capture for the improvement of understanding regulatory processes for learning.

\section{Cognitive engagement and the development of group cohesion}

The paper by Maia Altebarmakian and Rick Alterman studies group cohesion in online environments. Cohesion is the measure of progress in small groups. Group cohesion depends on the students' engagement and collaboration, with a focus on content and meaningful collaborative efforts. The unit of analysis in the paper is group practice, which is one of the core units studied in CSCL research (Stahl 2015; Ingulfsen et al. 2018; Solli et al. 2018).

The overall research design for the study is design-based research, and the authors perform an indepth study of students' collaboration over a semester in the knowledge area of computer supported cooperation. The design of the educational activities were aimed for the creation of a fine-tuned balance between individual and collaborative tasks. It was within the students' collaborative work that they could identify if and how cohesion emerged. As part of the educational design, a number of tasks were given to students individually and in groups.

Altebarmakian and Alterman use both the quantitative measure of group cohesion and a qualitative analysis to understand how students took part in collaborative interaction. The results show that students varied in their engagement in reading and writing activities, and in whether they engaged with their own contributions or those of others students. The study shows very clearly that writing was important as a source of high cognitive engagement and that a high degree of cognitive performance was needed for group cohesion to develop. Such case studies contribute analysis of how real-life phenomena play out in instructional settings in higher education over a period of time which gives a high degree of ecological validity.

\section{Extending the unit of analysis: metacognition and physiological measures}

In the paper by Jonna Malmberg, Eetu Haataja, Tapio Seppänen, and Sanna Järvelä, they have explored whether it is possible to identify physiological measures of collaborative activities. An important theme in CSCL is monitoring collaboration and coordination related to both cognitive and non-cognitive interactive processes. Monitoring is conceptualized as a set of meta-cognitive processes in their paper, which is seen as an indicator for recognizing whether collaborative efforts succeed or fail.

The study's empirical design was based on a collaborative exam with three students in each group. Out of 31 participants, 12 students were part of the sample included in the study. The students took a class in advanced physics as a voluntary part of their studies. The study can be characterized as an explorative study that aimed to test the possibility of connecting content 
analysis with physiological measures (for other related studies, see Pijeira-Díaz et al. 2018). The physiological data was collected with multi-sensor wristbands, which tracked the students' electrodermal activity (EDA).

The metacognitive monitoring, physiological arousal, and physiological synchrony took place during the collaborative exam. The authors first identified the relationship between the monitoring processes and the physiological arousal, then they tried to identify whether there was physiological synchrony during the collaborative efforts. The authors did not find a systematic relationship between the monitored events and physiological synchrony. Following this finding, the authors questioned whether the EDA measurement was sensitive enough for the phenomena that were explored.

One interesting hypothesis that arose from this study was whether monitoring made the students aware of the need to work differently in their collaborative efforts, which then may have created student arousal. However, since the study's authors did not find a connection between arousal and the regulation of learning, we need to be cautious about how to create our unit of analysis and our interpretations.

Another important CSCL theme that this study raised was related to how we identify emotional aspects of collaborative activities. A physiological measure might be one possible direction, but other approaches should also be considered. As the authors have said, their paper is part of a field that is in its infancy, which means that new studies are needed to make further progress.

Acknowledgments First, I would like to acknowledge the collaborations with the executive editors Ulrike Cress, Nancy Law, Carolyn P. Rosé and Gerry Stahl and their contributions to writing editorials, reviewing and discussing policies for the IJCSCL. The associate editors Carol Chan, Sanna Järvelä, Peter Reiman, Nikol Rummel and Baruch Schwarz have also worked effectively to review a high number of papers and address important issues for both individual papers and the CSCL field. I thank the editorial board and the reviewers who have worked during this four-year period. Without a high number of dedicated researchers who take the review processes very seriously, the IJCSCL would not be the highly ranked educational and interdisciplinary journal that it is today.

Dr. Rolf Steier has served as the journal's managing editor from 2016 to 2019. Rolf started this position as a post-doctoral fellow and is now an associate professor in the Department of Educational Sciences at the University of Oslo. To have a managing director who can master the content and language and also follow up with all the authors who publish their papers in IJCSCL is absolutely essential; that is, to have a CSCL researcher as a managing editor makes the editors' work easier. I am deeply grateful for the work that Rolf has done for the IJCSCL and for our collaboration over these four years.

I hope that the new Editors-In-Chief, Professor Sanna Jävelä and Professor Carolyn P. Rosé will continue to develop the CSCL field both through incremental developments and important innovations over the next four-year period.

\section{References}

Bowker, J., \& Star, S. L. (1999). Sorting things out: Classification and its consequences. Cambridge: MIT Press. Bygstad, B., Hanseth, O. (2018). Transforming digital infrastructures through platformization. ECIS Proceedings, Association for Information Systems.

Donald, M. (1991). Origins of the modern mind. Three stages in the evolution of culture and cognition. Cambridge: Harvard University Press.

Fischer, F., Goldman, S. R., Hmelo-Silver, C. E., \& Reimann, P. (2018). Introduction: Evolution of research in the learning sciences. In International handbook of the learning sciences (pp. 1-8). Chicago, Routledge.

Hadwin, A. F., Bakhtiar, A., \& Miller, M. (2018). Challenges in online collaboration: Effects of scripting shared task perceptions. International Journal of Computer-Supported Collaborative Learning, 13(3), 301-329.

Hod, Y., Sagy, O., \& Kali, Y. (2018). The opportunities of networks of research-practice partnerships and why CSCL should not give up on large-scale educational change. International Journal of Computer-Supported Collaborative Learning, 13(4), 457-466. 
Holtz, P., Kimmerle, J., \& Cress, U. (2018). Using big data techniques for measuring productive friction in mass collaboration online environments. International Journal of Computer-Supported Collaborative Learning, 13(4), 439-456.

Ingulfsen, L., Furberg, A., \& Strømme, T. (2018). Students' engagement with real-time graphs in CSCL settings: Scrutinizing the role of teacher support. International Journal of Computer-Supported Collaborative Learning, 13(4), 365-390.

Järvelä, S., Kirschner, P. A., Hadwin, A., et al. (2016). Socially shared regulation of learning in CSCL: Understanding and prompting individual- and group-level shared regulatory activities. International Journal of Computer-Supported Collaborative Learning, 11, 263.

Ludvigsen, S., \& Arnseth, H. A. (2017). Computer-supported collaborative learning. In E. Duval, M. Sharples, \& R. Sutherland (Eds.), Technology enhanced learning (pp. 47-58). Cham: Springer International

Matuk, C., Tissenbaum, M. \& Schneider, B. (2019). Real-time orchestrational technologies in computersupported collaborative learning: an introduction to the special issue. International Journal of ComputerSupported Collaborative Learning. https://doi.org/10.1007/s11412-019-09310-5

NOU 2015: 8. (2015). The School of the Future: Renewal of subjects and competence. Oslo. Norwegian Ministry of Education and Research. https://www.regjeringen.no/en/dokumenter/nou-2015-8/id2417001/

Pijeira-Díaz, H. J., Drachsler, H., Järvelä, S., \& Kirschner, P. A. (2018). Sympathetic arousal commonalities and arousal contagion during collaborative learning: How attuned are triad members? Computers in Human Behavior, 92, 188-197.

Roberts, J., \& Lyons, L. (2017). The value of learning talk: Applying a novel dialogue scoring method to inform interaction design in an open-ended, embodied museum exhibit. International Journal of ComputerSupported Collaborative Learning, 12(4), 343-376.

Rommetveit, R. (1998). On divergent perspectives and controversial issues in studies of language and mind. In M. Janse \& A. Verlinden (Eds.), Productivity and creativity (pp. 179-189). Berlin: Mouton deGruyter.

Silvis, D., Taylor, K. H., \& Stevens, R. (2018). Community technology mapping: Inscribing places when "everything is on the move". International Journal of Computer-Supported Collaborative Learning, $13(2), 137-166$.

Slakmon, B., \& Schwarz, B. B. (2014). Disengaged students and dialogic learning: The role of CSCL affordances. International Journal of Computer-Supported Collaborative Learning, 9(2), 157-183.

Solli, A., Mäkitalo, Å., \& Hillman, T. (2018). Rendering controversial socioscientific issues legible through digital mapping tools. International Journal of Computer-Supported Collaborative Learning, 13(4), 391418 .

Stahl, G. (2015). Conceptualizing the intersubjective group. International Journal of Computer-Supported Collaborative Learning, 10(3), 209-217.

Steier, R., Kersting, M., \& Silseth, K. (2019). Imagining with improvised representations in CSCL environments. International Journal of Computer-Supported Collaborative Learning, 14(1), 109-136.

Tchounikine, P. (2019). Learners' agency and CSCL technologies: towards an emancipatory perspective. International Journal of Computer-Supported Collaborative Learning, 14(2), 237-250.

Tomasello, M. (1999). The cultural origins of human cognition. Cambridge, MA: Harvard University Press.

White, T. (2018). Connecting levels of activity with classroom network technology. International Journal of Computer-Supported Collaborative Learning, 13(1), 93-122.

Wise, A. F., \& Schwarz, B. B. (2017). Visions of CSCL: Eight provocations for the future of the field. International Journal of Computer-Supported Collaborative Learning, 12(4), 423-467.

Yang, Y., van Aalst, J., Chan, C. K., \& Tian, W. (2016). Reflective assessment in knowledge building by students with low academic achievement. International Journal of Computer-Supported Collaborative Learning, 11(3), 281-311.

Publisher's note Springer Nature remains neutral with regard to jurisdictional claims in published maps and institutional affiliations. 